\title{
Catalytic Activity and Stability of Carbon Supported V Oxides and Carbides Synthesized via Pyrolysis of MIL-47 (V)
}

\author{
Jongsik Kim, ${ }^{a}$ Nicholas D. McNamara, ${ }^{a}$ and Jason C. Hicks ${ }^{a, *}$ \\ ${ }^{a}$ Department of Chemical and Biomolecular Engineering, University of Notre Dame, 182, Fitzpatrick Hall, \\ Notre Dame, IN, 46556, USA. \\ * corresponding author \\ Email: $\quad$ hicks3@nd.edu \\ Fax: $\quad$ (+1) 574-631-8366 \\ Tel: $\quad$ (+1) $574-631-1334$
}

\begin{abstract}
Substantial leaching of active $V$ species often limits the reusability of V-based soild catalysts in liquidphase oxidation reactions and therefore requires the development of more stable, novel materials. This paper first reports the synthesis of active vanadium (V) oxide and carbide species dispersed on a carbon support via the pyrolysis of MIL-47 (V), a V-based metal-organic framework (MOF) template. The phase transition of $\mathrm{V}$ species present in this MOF template was achieved by varying the pyrolysis temperatures ranging from 600 to $1100{ }^{\circ} \mathrm{C}$ to synthesize a series of carbon catalysts with different surface and bulk phases of V. Notably, the pyrolysis of MIL-47 (V) provided carbon supports with high surface areas ( $\left.350 \mathrm{~m}^{2} \mathrm{~g}^{-1}\right)$, high mesoporosities $\left(\mathrm{V}_{\text {MESO }} / \mathrm{V}_{\text {PORE }} \sim 0.88\right)$, high $\vee$ quantities (35-70 wt. \%), and small ( $18 \mathrm{~nm}$ ) $\mathrm{V}$ crystallites dispersed on the surface. These desired properties were not observed when $\mathrm{V}$ was supported on activated carbon (V/AC) via conventional impregnation. The V/AC catalyst showed lower mesoporosity ( $\sim 0.63$ ), lower $\vee$ quantity ( $25 \mathrm{wt} . \%$ ), and larger $V$ crystallites ( $27 \mathrm{~nm}$ ) compared to the catalyst produced from MIL-47 (V) pyrolysis under identical conditions. Of additional note, the pyrolysis of MIL-47 (V) could yield an isolated bulk phase of $\mathrm{V}$ carbide at low pyrolysis temperatures (i.e., $>900{ }^{\circ} \mathrm{C}$ ). This phase was not attainable when V/AC was synthesized via pyrolysis even at higher temperatures (i.e., $1100^{\circ} \mathrm{C}$ ). The catalytic performance of the resulting $\mathrm{V}$ on carbon catalysts was evaluated in a liquidphase oxidation reaction of dibenzothiophene. The $V$ carbide catalysts exhibited good activities and enhanced stabilities, as evidenced by lower amounts of $V$ species leached $(<20 \%)$ during recycle runs compared to the conventional V/AC catalyst (V leaching 56\%). This study marks a signifcant improvement in the synthesis of supported $V$ catalysts with reduced leaching in liquid-phase oxidation reactions compared to materials synthesized via conventional impregnation techniques.
\end{abstract}




\section{Keywords}

reaction kinetics, metal-organic frameworks, pyrolysis, $\mathrm{V}$ carbide, dibenzothiophene oxidation

\section{Introduction}

Vanadium-based solid materials have received significant attention as heterogeneous catalysts due to their high activity in liquid-phase oxidation reactions. More specifically, they have been studied as catalysts for the oxidation of S-heterocycles [1-4], carbocycles [5-7], alcohols [8-10], and aromatics [11]. However, as shown in Table S1, these V-based catalysts typically suffer from significant leaching of V species (20-90 mol. \%) during liquid-phase oxidation reactions when peroxides are used as oxidants [1, 5, $6,11-20]$. This phenomenon, unfortunately, limits the practical applications of these materials because it significantly reduces their lifetimes as catalysts and requires additional separation processes to remove leached $V$ species from the liquid phase $[13,20]$. Furthermore, many hot filtration studies have been reported that suggest leached $\mathrm{V}$ species were responsible for catalysis rather than the solid materials themselves $[1,6,11,15,20]$.

In order to overcome this limitation, the determination of stable yet active $\mathrm{V}$ phases on the catalyst surface is paramount. For instance, different phases of vanadium oxides (e.g., $\mathrm{V}_{2} \mathrm{O}_{5}, \mathrm{VO}_{2}$, and $\mathrm{V}_{2} \mathrm{O}_{3}$ ) were reported to have distinct properties in terms of their electronics [21, 22], structural geometry [22, 23], and defect formation [21], all of which have significant effects on their stabilities for oxidation reactions [21-24]. Transition metal carbides comprise one class of particularly promising heterogeneous catalytic phases due to their higher thermal and chemical stabilities than their analogous oxide phases [25-30]. Moreover, these carbide phases can also exhibit high catalytic activity in redox reactions due to their unique carbon-modified structures, which often resemble that of noble metals [31-34]. 
In addition to the formation of desired $\mathrm{V}$ phases for the liquid-phase oxidation reactions, the selection of a catalyst support that can strongly immobilize the active $\mathrm{V}$ phase is also essential [20]. It should be noted that there have been substantial synthetic efforts to minimize $V$ leaching from various silicate-based catalysts via V-tethering [13], grafting [11], incorporation [5, 11, 16], and immobilization $[11,15,17]$. However, the loss of active $V$ species during the reactions was unavoidable due possibly to insufficient chemical stability between silicate and $V$ species under the reaction conditions employed (Table S1) [20, 35-37]. Carbon is a promising support material because it can provide several advantages such as high surface area [38-40], high dispersion of active $V$ species $[25,41]$, high resistance to thermochemical oxidation [42-44], and compatibility with a wide range of active $V$ phases [25, 45]. In particular, the interaction between active $\mathrm{V}$ species and carbon can be promoted via pyrolysis under an inert atmosphere, wherein $\mathrm{V}$ precursors are carbothermally reduced by carbon to generate reduced $\mathrm{V}$ nanoparticles embedded in holes on the carbon surface $[25,38,46]$.

Herein, to attain $V$ on carbon catalysts with desired properties via pyrolysis, we detailed the use of a V-incorporated metal-organic framework (MOF), MIL-47 (V), as a template. The pyrolysis of a MOF with site-isolated metal species via coordination to organic linkers has been demonstrated to provide the resulting carbon materials with high surface areas [44, 47], high mesoporosities [25, 38], high metal loadings [ 48,49$]$, and moderate-sized metal nanoparticles [48, 50, 51]. As shown in Fig. 1a, MIL-47 is a vanadium-based MOF composed of VO centers (V precursors) interconnected by 1,4benzenedicarboxylate (BDC) linkers to form a three-dimensional, orthorhombic, porous solid with a base unit of $V^{\prime V} O(B D C)[52]$. The high loading of $V$ species within the MIL-47 (V) template ( $4300 \mu \mathrm{mol} \mathrm{V} \mathrm{g}^{-1}$ ) [52] was expected to yield a carbon material with high loadings of $V$ after pyrolysis (Fig. 1b). Additionally, previous pyrolysis studies of various MOFs suggested the porous architecture of MIL-47 (V) can be retained during pyrolysis, which provided high surface areas of the resulting carbon [44, 47]. 
Furthermore, the carbon consumption via carbonization of the BDC linkers and carbothermal V reduction during the MIL-47 (V) pyrolysis is potentially capable of generating mesopores, which was also observed in our previous works involving the pyrolysis of $\mathrm{Zn}$ and Ti-based MOFs (e.g., metal-modified IRMOF-3 [25, 38, 39] and MIL-125 (Ti)[48]). Expectedly, moderate-sized V nanoparticles can be achievable based on their confinement in the carbon holes, as previously discussed. This confinement was also anticipated to enhance the stability of active $V$ species during the reactions [53]. Most importantly, manipulation of the $\mathrm{V}$ phase from various oxide forms to the carbide could be also accomplished through the variation of the pyrolysis temperature of MIL-47 (V) (Fig. 1C).

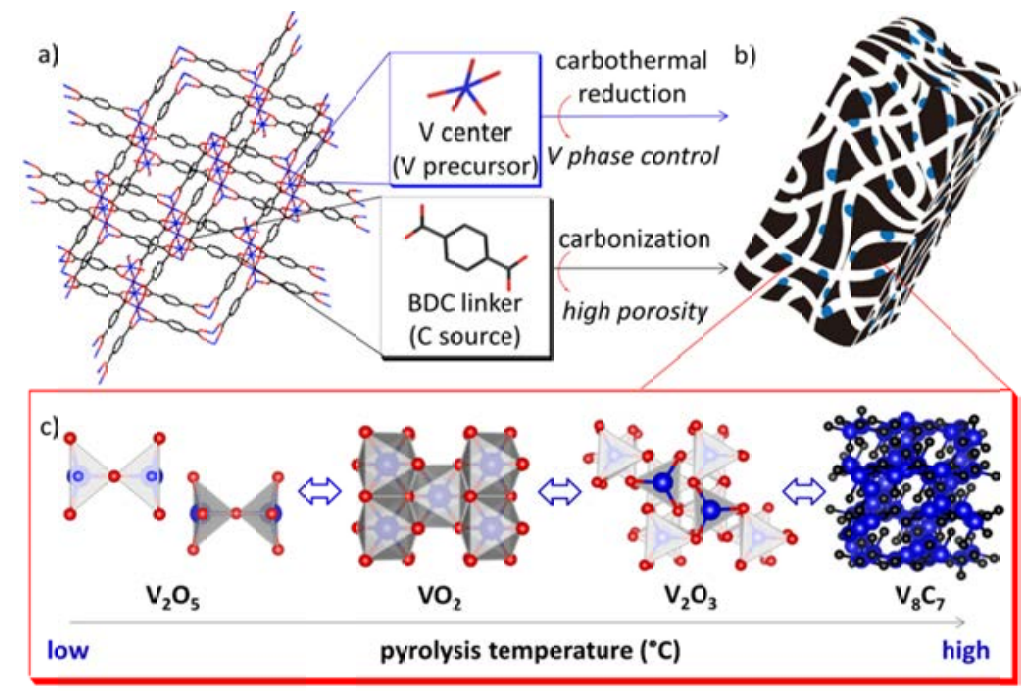

Fig. 1. Schematic representation of a) MIL-47 (V) pyrolyzed to form b) carbon supporting V nanoparticles with c) variable phases.

This study highlights the formation and characterization of a new class of carbon catalysts with various phases of $\mathrm{V}$ nanoparticles. These materials were also evaluated as catalysts in the liquid-phase oxidation of dibenzothiophene (DBT) with tert-butyl hydroperoxide (TBHP). It is noteworthy that the use of carbon-supported $\mathrm{V}$ catalysts (in particular, $\mathrm{V}$ carbide) has not been studied yet for this reaction, to the best of our knowledge. The properties and the catalytic performance of these carbon catalysts were 
also compared to $\mathrm{V}$ on activated carbon synthesized via a conventional impregnation method as a control catalyst to simulate typical commercial carbon-based catalysts.

\section{Experimental}

\subsection{Chemicals}

The following chemicals were purchased commercially and used as received: $\mathrm{VCl}_{3}$ (Alfa Aesar, $99 \%$, metal basis), 1,4-benzenedicarboxylic acid (Aldrich, $98 \%$ ), N,N-dimethylformamide (EMD, ACS grade), VO(O-iPr) 3 (Alfa Aesar, 96\%), vanadium ICP standard (J.T. Baker, $1000 \mu \mathrm{g} / \mathrm{mL}$ ), acetone (EMD, ACS grade), chloroform (Alfa-Aesar, ACS grade), $n$-decane (Alfa Aesar, $99 \%$ ), $n$-dodecane (Alfa-Aesar, 99+ \%), dibenzothiophene (Acros, $99 \%$ ), Celite ${ }^{\circledR} 545$ (EMD), and tert-butyl hydroperoxide (5.0-6.0 M in decane, Aldrich). Activated carbon (DARCO ${ }^{\circledR},-100$ mesh particle size, Sigma-Aldrich) was dehydrated at $125^{\circ} \mathrm{C}$ for 10 hours using a Schlenk line to eliminate $\mathrm{H}_{2} \mathrm{O}$ physisorbed on the carbon surface and subsequently stored in a glove box purged with $\mathrm{N}_{2}(>99 \%)$.

\subsection{Characterization}

The surface areas and pore volumes of catalysts were estimated via the adsorption of $\mathrm{N}_{2}$ at $77 \mathrm{~K}$ using a Quantachrome NOVA 2200e. Catalysts were dried at $125^{\circ} \mathrm{C}$ under dynamic vacuum of $10^{-3}$ torr for 18 hours prior to the analysis. Surface areas $\left(\mathrm{S}_{\mathrm{NLDFT}}\right)$ of the catalysts were estimated using nonlocal density functional theory (NLDFT) based on the volume of $\mathrm{N}_{2}$ adsorbed under the pressure range between $1 \mathrm{X}$ $10^{-4}<\mathrm{P} / \mathrm{P}_{0}<1.0$. The pore volumes of the catalysts were calculated using NLDFT under the assumption that pores were slit-shaped nanopores [54]. The total pore volume $\left(\mathrm{V}_{\text {PORE }}\right)$ of each catalyst was acquired from the summation of micropore volume $\left(V_{\text {MICRO }}\right.$ with the pore size less than $\left.2 \mathrm{~nm}\right)$ and mesopore volume $\left(\mathrm{V}_{\mathrm{MESO}}\right.$ with the pore size between 2 and $\left.50 \mathrm{~nm}\right)$. X-ray diffraction (XRD) patterns of the synthesized catalysts were acquired using a D8 Advance Davinci diffractometer operated at $40 \mathrm{kV}$ and 40 
$\mathrm{mA}$ with monochromated CuKa radiation $(\lambda=1.5418 \AA)$ and with a scan speed of 2.0 second per step and a step size of $0.02^{\circ}$ per step. Thermogravimetric analysis (TGA) of the synthesized catalysts was performed using a Mettler-Toledo TGA/DSC STAR System to investigate the loading of V (wt. \%) (M.W. denotes molecular weight) based on the fact that heating of these catalysts under an air flow of $50 \mathrm{~mL}$ $\min ^{-1}$ generated $\mathrm{V}_{2} \mathrm{O}_{5}$ (eqn. (1)) $[25,38,55]$.

$$
\text { V (wt. \%) }=100 \times \frac{2 \times(\mathrm{M} . \mathrm{W} . \text { of } \mathrm{V})}{\mathrm{M} . \mathrm{W} \text {. of } \mathrm{V}_{2} \mathrm{O}_{5}} \times \frac{\text { final weight of catalyst after heating in air }}{\text { initial weight of catalyst }}
$$

High resolution transmission electron microscopy (HRTEM) analysis was conducted using a FEI Titan Microscope operating at $300 \mathrm{keV}$ for the estimation of $\mathrm{V}$ nanoparticle size on the catalysts, where the number of $V$ nanoparticles analyzed was 150. Prior to the HRTEM analysis, a suspension of these catalysts in acetone was dropped onto a copper grid with a holey carbon support then dried at $40{ }^{\circ} \mathrm{C}$ under vacuum ( $10^{-2}$ torr) for 18 hours. Size distributions of $V$ nanoparticles were evaluated using the Feret function of ImageJ software (ver. 1.46). The average size of $V$ crystallites (d) was also estimated using the Scherrer equation, where $K$ indicates the dimensionless shape factor $(0.89), \lambda$ denotes the $X-$ ray wavelength $(0.15418 \mathrm{~nm}), \beta$ indicates the line broadening (radian) at half the maximum intensity, and $\theta$ denotes the Bragg angle of the facet with the most dominant intensity $\left(2 \theta\right.$ of $55.0^{\circ}(-222)$ for $\mathrm{VO}_{2}$

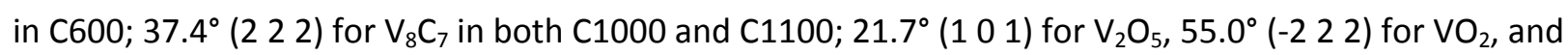
$37.4^{\circ}\left(\begin{array}{lll}2 & 2 & 2\end{array}\right)$ for $V_{8} C_{7}$ in $\left.V / A C\right)$ (eqn. (2))

$$
\mathrm{d}=\frac{K \times \lambda}{\beta \times \cos \theta}(2)
$$

X-ray photoelectron spectroscopy (XPS) analysis of the catalysts was performed on a PHI VersaProbe II X-ray photoelectron spectrometer in order to observe the relative abundance of surface phases of $\mathrm{V}$. Measurements were performed after the catalysts dispersed on carbon tape were exposed to ultra-high 
vacuum ( $10^{-8}$ torr) in order to clean the surface of the catalysts. The binding energy of amorphous carbon located at $284.5 \mathrm{eV}$ was used as a reference during the measurement of each catalyst. The leached amount of $\mathrm{V}$ species after the reaction was estimated using a Perkin Elmer Optima 3300XL inductively coupled plasma-optical emission spectrometer (ICP-OES). External V standards were prepared and used to generate a calibration curve. Prior to quantifying the leached $\mathrm{V}$ species, the solid catalyst was removed from the reaction mixture through vacuum filtration. This leached $V$ amount was calculated as a mole percent of $\mathrm{V}(\mathrm{mol} . \%)$, which was determined based on the amount of $\mathrm{V}$ used in each reaction run (Table S2). Gas chromatography (GC) with flame ionization detector (FID) was used to estimate the catalytic performance (i.e., conversion and yield) of the catalysts based on the quantification of the reactant concentration (dibenzothiophene, DBT) using an internal standard (dodecane) (eqn. (3)-(5)).

$$
\begin{gathered}
\text { conversion }(\%)=(\underbrace{\frac{\text { area of } D B T}{\text { area of dodecane }}}_{\text {before reaction }}-\underbrace{\frac{\text { area of DBT }}{\text { area of dodecane }}}_{\text {after reaction }}) \div(\underbrace{\frac{\text { area of DBT }}{\text { area of dodecane }}}_{\text {before reaction }}) \times 100(3) \\
\text { selectivity }(\%)=\frac{\text { moles of product formed }}{\text { moles of DBT converted }} \times 100(4) \\
\text { yield }(\%)=\text { conversion } \times \text { selectivity } \times 10^{-4}(5)
\end{gathered}
$$

The reaction mixture was taken in a predetermined time interval and subsequently analyzed by its injection into an Agilent Technologies model 7820A GC with a (5\%-phenyl)-methylpolysiloxane column (length of $30 \mathrm{~m}$; diameter of $0.32 \mathrm{~mm}$ ) and FID. The temperature of the column was held at $50{ }^{\circ} \mathrm{C}$ for 3 minutes and then increased to $280^{\circ} \mathrm{C}$ at a ramp rate of $15^{\circ} \mathrm{C} \mathrm{min}{ }^{-1}$. The $\mathrm{GC}$ injector temperature was set to $150{ }^{\circ} \mathrm{C}$. The carrier gas stream was composed of He with a constant flow rate of $0.5 \mathrm{~mL} \mathrm{~min}{ }^{-1}$.

\subsection{Synthesis of MIL-47 (V)}


MIL-47 (V) was synthesized according to a modified procedure reported by Férey and co-workers [52]. A mixture comprised of $8.65 \mathrm{mmol}$ of $\mathrm{VCl}_{3}, 1.55 \mathrm{mmol}$ of 1,4-benzenedicarboxylic acid, and $14.7 \mathrm{~g}$ of deionized water was added to $44 \mathrm{~mL}$ Teflon acid digestion sleeve and stirred for 15 minutes. The Teflon sleeve was then placed in a stainless steel reactor vessel and heated at $200^{\circ} \mathrm{C}$ for 5 days. After cooling to $25^{\circ} \mathrm{C}$, the resulting light green solid was collected using vacuum filtration and washed several times using $200 \mathrm{~mL}$ of acetone. To synthesize activated MIL-47 (V), as-synthesized MIL-47 (V) was subjected to calcination under the following condition: $200{ }^{\circ} \mathrm{C}$ for an hour followed by $300^{\circ} \mathrm{C}$ for 24 hours.

\subsection{Pyrolysis of activated MIL-47 (V)}

Pyrolysis of activated MIL-47 (V) was performed according to the procedure we previously employed $[25,38,56]$. The activated MIL-47 (V) was loaded into a tube furnace (Thermo Scientific Lindberg Blue M) and subjected to pyrolysis under an Ar flow of $30 \mathrm{~mL} \mathrm{~min}^{-1}$ with a ramp rate of $10{ }^{\circ} \mathrm{C} \mathrm{min}^{-1}$ to the target temperatures ranging from $600{ }^{\circ} \mathrm{C}$ to $1100{ }^{\circ} \mathrm{C}$ held for 6 hours. This led to the formation of the carbon catalyst denoted as CXXX, where XXX indicates the target temperature used during pyrolysis (e.g., C700 indicates the catalyst derived from the pyrolysis of activated MIL-47 (V) at $700{ }^{\circ} \mathrm{C}$ for 6 hours). After cooling to $25^{\circ} \mathrm{C}$ under an Ar atmosphere, the resulting catalyst was passivated under a $1 \%$ of $\mathrm{O}_{2}$ in He with a flow rate of $10 \mathrm{~mL} \mathrm{~min}^{-1}$ for 1.5 hours prior to exposure to an ambient atmosphere $[25,57]$.

\subsection{Synthesis of V/AC}

Vanadium on activated carbon (V/AC), a control material, was synthesized via a conventional impregnation method slightly modified based on our previous procedure performed in a glove box [25, 38]. Approximately $0.5 \mathrm{~g}$ of desolvated $\mathrm{AC}$ was added in a bottle, subsequently impregnated using 1.425 $\mathrm{mmol}$ of $\mathrm{VO}(\mathrm{O}-\mathrm{iPr})_{3}$, and stored inside the glove box overnight. The amount of $\mathrm{VO}(\mathrm{O}-\mathrm{iPr})_{3}$ used during the impregnation was the maximum quantity of the $\mathrm{V}$ precursor that can be confined in the nanopores 
of the AC. The maximum amount of the $\mathrm{V}$ precursor was determined via calibration prior to the impregnation. The impregnated $A C$ was then loaded in a tube furnace, pyrolyzed, and passivated by following the identical procedure as that used to synthesize $\mathrm{C} 1100$. This ultimately led to the generation of V/AC.

\subsection{Oxidation of dibenzothiophene}

The catalytic performance of the synthesized catalysts was evaluated according to a slightly modified procedure we previously reported $[1,38,58]$. In a typical catalytic reaction (the $1^{\text {st }}$ run), a mixture composed of $3.5 \mathrm{mmol}$ of dibenzothiophene (DBT), $21.9 \mathrm{~g}$ of decane (solvent), and $0.5 \mathrm{~g}$ of dodecane (internal standard) was loaded in a $100 \mathrm{~mL}$ round bottom flask and stirred at $104( \pm 1)^{\circ} \mathrm{C}$ for an hour before $7.525 \mathrm{mmol}$ of tert-butyl hydroperoxide (TBHP, oxidant) was added to the flask (molar ratio of reactant: oxidant $=1: 2.15)$. Once the reaction temperature was stabilized after 15 minutes, the catalyst (8.1 mg for MIL-47; $5 \mathrm{mg}$ for C600; $2.3 \mathrm{mg}$ for C1000 and C1100; $6.3 \mathrm{mg}$ for V/AC) was carefully added. Approximately $0.5 \mathrm{~mL}$ aliquots of the reaction mixture was then taken at predetermined time intervals (C600 and V/AC for 1 minute; activated MIL-47 (V), C1000, and C1100 for 2 minute), transferred to a GC vial, and diluted with decane for the estimation of catalytic performance for each catalyst using GC-FID. In a typical recycle test, the catalytic reaction at each cycle (i.e., the $2^{\text {nd }}$ and the $3^{\text {rd }}$ run) was performed under identical conditions (e.g., identical amount of catalyst) as that employed during the $1^{\text {st }}$ run. Each cycle was repeated three times in order to collect enough catalyst for the next recycle run and to confirm the reproducibility of the results. After the reaction, the catalyst was collected by vacuum filtration using a Whatman filter paper (Grade 5, pore size: $2.5 \mu \mathrm{m}$ ) and washed with $100 \mathrm{~mL}$ of N,Ndimethylformamide and $100 \mathrm{~mL}$ of chloroform. Recovered catalyst was then dried in a vacuum oven at $40{ }^{\circ} \mathrm{C}$ for 18 hours. In a typical hot filtration test at $74( \pm 1)^{\circ} \mathrm{C}$, the catalyst was removed from the reaction mixture after 15 minutes by filtering the reaction mixture over Celite ${ }^{\circledR} 545$ (20 g). Afterwards, 
the collected reaction mixture was further monitored at $74( \pm 1){ }^{\circ} \mathrm{C}$. Notably, during the hot filtration study, the reaction temperature was decreased from $104( \pm 1)^{\circ} \mathrm{C}$ to $74( \pm 1){ }^{\circ} \mathrm{C}$, while changing the sampling time interval from 1 (or 2) minute to 5 minute to minimize the effect potentially caused by the time taken to perform the hot filtration, thereby obtaining more feasible results.

\section{Results and discussion}

\subsection{Catalyst synthesis and characterization}

As a control to simulate a typical commercial carbon-supported catalyst, $\mathrm{V}$ on activated carbon (V/AC) was first synthesized via conventional impregnation and subsequent pyrolysis following an identical procedure as that used to generate $\mathrm{C} 1100$. A temperature of $1100^{\circ} \mathrm{C}$ was selected for pyrolysis because C1100 showed a strong balance of activity and stability in the oxidation of DBT, which is discussed in a later section of this study. Of note, in our previous study, impregnated V/AC could not yield V carbide species after pyrolysis at $1000{ }^{\circ} \mathrm{C}[25]$ and therefore $1100{ }^{\circ} \mathrm{C}$ was employed as the pyrolysis temperature for a more accurate comparison of properties and catalytic performance between V/AC and C1100. For the preparation of V-incorporated carbon catalysts, we hydrothermally synthesized MIL-47 (V) using $\mathrm{VCl}_{3}$ and 1,4-benzenedicarboxylic acid as the sources for the $\mathrm{V}$ center and the organic linker (BDC), respectively [52]. This material was subsequently calcined at $300{ }^{\circ} \mathrm{C}$ to eliminate free BDC linkers occupying the pores of as-synthesized MIL-47 (V) to yield activated MIL-47 (V) [1, 52]. The formation of activated MIL-47 (V) was confirmed by its powder X-ray diffraction (XRD) pattern, which was in agreement with the simulated pattern (Fig. S1a) [52]. The retention of the microporous structure after the activation was also validated by $\mathrm{N}_{2}$ physisorption (Table 1 and Fig. S1b), which provided a surface

area $\left(\mathrm{S}_{\mathrm{NLDF}}\right)$ of $510 \mathrm{~m}^{2} \mathrm{~g}^{-1}$ as well as micropore volume $\left(\mathrm{V}_{\mathrm{MICRO}}\right)$ of $0.21 \mathrm{~cm}^{3} \mathrm{~g}^{-1}$, estimated using nonlocal density functional theory (NLDFT). The activated MIL-47 (V) was pyrolyzed at different maximum temperatures between $600{ }^{\circ} \mathrm{C}$ and $1100^{\circ} \mathrm{C}$ for 6 hours to form the carbon catalysts denoted as C600- 
C1100. A temperature of $600^{\circ} \mathrm{C}$ was selected as the lowest temperature limit in this pyrolysis because thermal decomposition of the MIL-47 (V) involved the carbonization of the organic BDC linkers to form the carbon support below $600{ }^{\circ} \mathrm{C}$. From the differential thermogravimetric (DTG) profile of the activated MIL-47 (V) under a $\mathrm{N}_{2}$ atmosphere (Fig. S1c), no significant changes were observed in the weight loss of the material at temperatures of $580^{\circ} \mathrm{C}$ or higher.

All pyrolyzed MIL-47 (V) catalysts showed moderate surface areas of 300-400 $\mathrm{m}^{2} \mathrm{~g}^{-1}$ and pore volumes ranging from 0.6 to $0.9 \mathrm{~cm}^{3} \mathrm{~g}^{-1}$ (Table 1 and Fig. S2). In addition, in spite of showing a lower surface area compared to the V/AC (620 $\mathrm{m}^{2} \mathrm{~g}^{-1}$, Fig. S4a), the pyrolyzed MIL-47 (V) analogue (i.e., C1100) showed enhanced pore volume $\left(\mathrm{V}_{\mathrm{PORE}} \sim 0.9 \mathrm{~cm}^{3} \mathrm{~g}^{-1}\right)$ and mesoporosity $\left(\mathrm{V}_{\mathrm{MESO}} / \mathrm{V}_{\mathrm{PORE}} \sim 0.9\right.$, ratio of mesopore volume to total pore volume) over the $\mathrm{V} / \mathrm{AC}\left(\mathrm{V}_{\mathrm{PORE}} \sim 0.6 \mathrm{~cm}^{3} \mathrm{~g}^{-1}, \mathrm{~V}_{\mathrm{MESO}} / \mathrm{V}_{\mathrm{PORE}} \sim 0.6\right)$ [25]. Notably, the large quantity of V ( 22.1 wt. \%) innate to the activated MIL-47 (V) prior to pyrolysis led to significant V loadings on the synthesized catalysts after pyrolysis (Table 1 and Fig. S3). The amount of $V$ in the materials increased from $36.1 \mathrm{wt}$ \% to $68.1 \mathrm{wt}$ \% as the pyrolysis temperature was increased from $600{ }^{\circ} \mathrm{C}$ to $1100^{\circ} \mathrm{C}$. This increase was associated with the consumption of the $\mathrm{C}$ source caused by the carbothermal reduction of $\mathrm{V}$ oxides to form more reduced $\mathrm{V}$ species ( $\mathrm{V}$ carbide), as discussed previously $[25,59,60]$. This consumption was more pronounced at higher pyrolysis temperatures, resulting in a greater loss of carbon leading to larger loadings of $V$ species on the catalysts $[59,60]$. In contrast, the maximum V loading attainable on AC via conventional impregnation was 25.0 wt. \% (Fig. S4b). Thus, pyrolysis of MIL-47 (V) can lead to higher V loadings on carbon supports than conventional impregnation techniques, which is advantageous because less material would be required in catalysis applications. 
Table 1. Physical properties of the catalysts.

\begin{tabular}{ccccccc} 
catalyst & $\begin{array}{c}\mathrm{S}_{\text {NLDFT }}{ }^{a} \\
\left(\mathrm{~m}^{2} \mathrm{~g}^{-1}\right)\end{array}$ & $\begin{array}{c}\mathrm{V}_{\text {MICRO }}{ }^{a} \\
\left(\mathrm{~cm}^{3} \mathrm{~g}^{-1}\right)\end{array}$ & $\begin{array}{c}\mathrm{V}_{\text {MESO }}{ }^{a} \\
\left(\mathrm{~cm}^{3} \mathrm{~g}^{-1}\right)\end{array}$ & $\begin{array}{c}\mathrm{V}_{\text {PORE }}{ }^{a} b \\
\left(\mathrm{~cm}^{3} \mathrm{~g}^{-1}\right)\end{array}$ & $\begin{array}{c}\mathrm{V}_{\text {MESO }} / \\
\mathrm{V}_{\text {PORE }}\end{array}$ & $\begin{array}{c}\text { V loading }^{c} \\
(\text { wt. \% })\end{array}$ \\
\hline MIL-47 (V) & 510 & 0.21 & - & 0.21 & - & 22.1 \\
C600 & 310 & 0.09 & 0.81 & 0.90 & 0.90 & 36.1 \\
C700 & 340 & 0.10 & 0.52 & 0.62 & 0.84 & 39.6 \\
C800 & 400 & 0.11 & 0.71 & 0.82 & 0.87 & 58.9 \\
C900 & 400 & 0.11 & 0.72 & 0.83 & 0.87 & 59.3 \\
C1000 & 310 & 0.07 & 0.82 & 0.89 & 0.92 & 59.9 \\
C1100 & 320 & 0.08 & 0.81 & 0.89 & 0.91 & 68.1 \\
V/AC & 620 & 0.23 & 0.39 & 0.62 & 0.63 & 25.0 \\
\hline
\end{tabular}

${ }^{a}$ via NLDFT. ${ }^{b} \mathrm{~V}_{\text {MICRO }}+\mathrm{V}_{\text {MESO }} \cdot{ }^{c}$ via TGA.

Powder XRD was used to investigate the bulk phases of $\mathrm{V}$ present in each of these catalysts (Fig. 2).

Catalysts pyrolyzed at $800^{\circ} \mathrm{C}$ or lower showed multiple diffractions that were assigned to bulk phases of monoclinic $\mathrm{VO}_{2}$ (JCPDS No.: 33-1441), rhombohedral $\mathrm{V}_{2} \mathrm{O}_{3}$ (JCPDS No.: 34-0187), or face-centered cubic (fcc) $\mathrm{V}_{8} \mathrm{C}_{7}$ (JCPDS No.: 35-0786). This was in contrast to the XRD patterns of the catalysts pyrolyzed at $900{ }^{\circ} \mathrm{C}$ or higher, which showed the sole presence of bulk $\mathrm{V}$ carbide, as indicated by the appearance of diffractions at $37.4^{\circ}, 43.4^{\circ}, 63.0^{\circ}$, and $75.6^{\circ}$ assigned to the (222), (400), (440), and (622) crystal planes of $\mathrm{fcc} \mathrm{V}_{8} \mathrm{C}_{7}$, respectively. Even though the $\mathrm{V} / \mathrm{AC}$ was also synthesized at $1100{ }^{\circ} \mathrm{C}$, this catalyst showed a variety of bulk $V$ phases evidenced by the diffractions assigned to orthorhombic $\mathrm{V}_{2} \mathrm{O}_{5}$, (JCPDS No.: 411426), monoclinic $\mathrm{VO}_{2}$, and fcc $\mathrm{V}_{8} \mathrm{C}_{7}$. These results suggested that the struction and location of $\mathrm{V}$ species in MIL-47 (V) played an important role in obtaining a $\mathrm{V}$ carbide phase at lower pyrolysis temperatures compared to the conventional impregnation synthesis, which is in agreement with our previous reports $[25,38,48]$. 


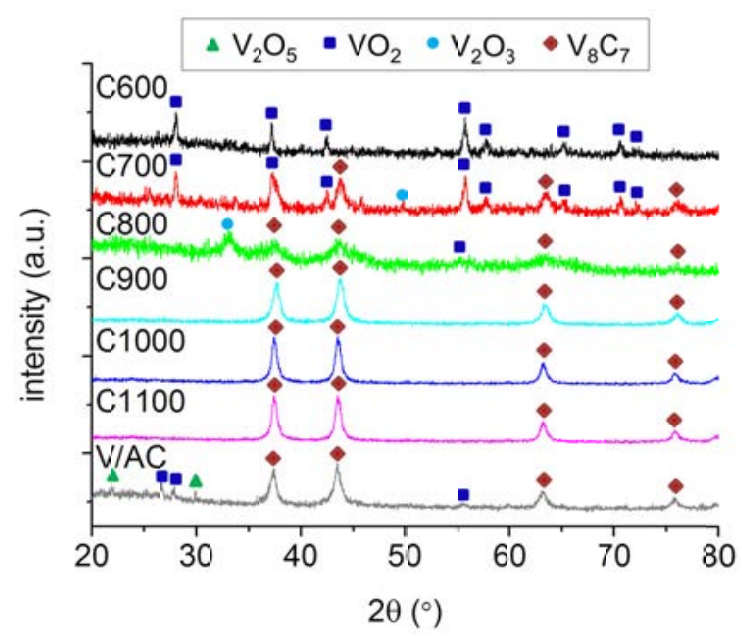

Fig. 2. XRD patterns of the catalysts.

To further investigate the phase transition of V in pyrolyzed MIL-47 (V) catalysts, we employed X-ray photoelectron spectroscopy (XPS). As displayed in Fig. 3, XP spectra of these catalysts clearly showed the transition of surface $V$ species from high oxidation states to low oxidation states as the pyrolysis temperature increased. In the $V 2 p_{3 / 2}$ region, the deconvoluted spectrum of $\mathrm{C} 600$ showed three peaks centered at binding energies of $517.0 \mathrm{eV}, 515.7 \mathrm{eV}$, and $514.9 \mathrm{eV}$ assigned to surface $\mathrm{V}$ phases of $\mathrm{V}_{2} \mathrm{O}_{5}$ $\left(\mathrm{V}^{5+}\right), \mathrm{VO}_{2}\left(\mathrm{~V}^{4+}\right)$, and $\mathrm{V}_{2} \mathrm{O}_{3}\left(\mathrm{~V}^{3+}\right)$ with relative abundances of $\sim 49 \%, \sim 32 \%$, and $\sim 19 \%$, respectively (Table 2). Upon increasing the pyrolysis temperature to $700{ }^{\circ} \mathrm{C}$, the surface $\mathrm{VO}_{2}\left(\mathrm{~V}^{4+}\right)$ species disappeared, which increased the relative abundances of $\mathrm{V}_{2} \mathrm{O}_{5}\left(\mathrm{~V}^{5+}\right)$ to $\sim 73 \%$ and $\mathrm{V}_{2} \mathrm{O}_{3}\left(\mathrm{~V}^{3+}\right)$ to $\sim 27 \%$. Interestingly, despite the absence of diffractions attributable to the bulk $\mathrm{V}_{2} \mathrm{O}_{5}$ phase in the XRD patterns of both $\mathrm{C} 600$ and $\mathrm{C} 700$, the presence of $\mathrm{V}_{2} \mathrm{O}_{5}\left(\mathrm{~V}^{5+}\right)$ was observed on these catalysts' surfaces shown in XP spectra. Furthermore, although $C 700$ contained the bulk phase of $V_{8} C_{7}$ as evidenced from $X R D$, the presence of a surface phase of $\mathrm{V}$ carbide $\left(\mathrm{V}^{\delta+}\right)$ was not observed in its $\mathrm{XP}$ spectrum (carbide peak is located between binding energies of $\sim 515 \mathrm{eV}$ and $\sim 512 \mathrm{eV}[25,61])$. These discrepancies between XRD patterns and XP spectra were previously reported in several studies investigating V-based MOFs and their pyrolyzed analogues using these analyses $[1,25,62]$. 


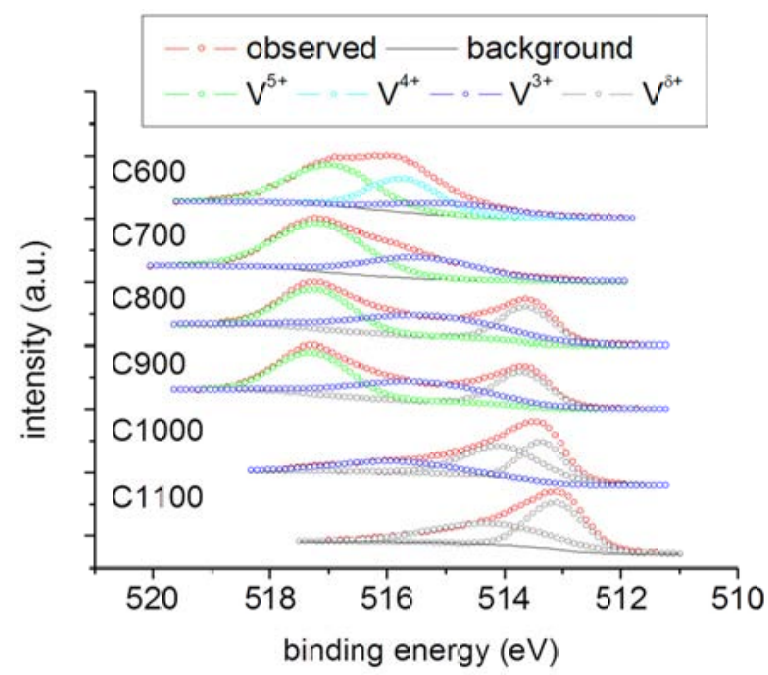

Fig. 3. V $2 p_{3 / 2}$ region of XP spectra of the pyrolyzed MIL-47 (V) catalysts.

Table 2. Relative abundance and $V 2 p_{3 / 2}$ shell binding energies of surface phases of $V$ on the pyrolyzed MIL-47 (V) catalysts by XPS. Values in parentheses indicate the binding energies of surface $V$ phases.

\begin{tabular}{ccccc} 
catalyst & $\begin{array}{c}\mathrm{V}^{5+} \\
(517 \mathrm{eV})\end{array}$ & $\begin{array}{c}\mathrm{V}^{4+} \\
(515.7 \mathrm{eV})\end{array}$ & $\begin{array}{c}\mathrm{V}^{3+} \\
(514.9 \mathrm{eV})\end{array}$ & $\begin{array}{c}\mathrm{V}^{\delta+} \\
(512-515 \mathrm{eV})\end{array}$ \\
\hline C600 & 48.7 & 32.2 & 19.1 & - \\
C700 & 72.8 & - & 27.2 & 35.7 \\
C800 & 45.3 & - & 19.0 & 33.6 \\
C900 & 42.8 & - & 23.6 & 88.0 \\
C1000 & - & - & 12.0 & 100 \\
C1100 & - & - & - & \\
\hline
\end{tabular}

However, in materials pyrolyzed at temperatures of $800^{\circ} \mathrm{C}$ and higher, a surface phase of $\mathrm{V}$ carbide $\left(\mathrm{V}^{\delta+}\right)$ was observed in XPS, which was also observable as a bulk phase in their XRD patterns (Fig. 2). The XP spectra of all catalysts pyrolyzed above $800{ }^{\circ} \mathrm{C}$, except for the $\mathrm{C} 1100$ catalyst, showed the presence of surface oxides due in part to the passivation of their carbide phases during synthesis. As the pyrolysis temperature was increased from $800^{\circ} \mathrm{C}$ to $900{ }^{\circ} \mathrm{C}$, the relative abundances of the $\mathrm{V}^{5+}, \mathrm{V}^{3+}$, and $\mathrm{V}^{\delta+}$ phases were relatively constant. After increasing the pyrolysis temperature to $1000^{\circ} \mathrm{C}$, however, a loss of the $\mathrm{V}^{5+}$ phase was observed, and a significant reduction in the relative abundance of the $\mathrm{V}^{3+}$ phase accompanied by an increase in the relative abundance of the $\mathrm{V}^{\delta+}$ phase was observed. The material 
pyrolyzed at a temperature of $1100{ }^{\circ} \mathrm{C}$ resulted in an XP spectrum that only showed a $\mathrm{V}^{\delta+}$ phase with no evidence of any oxide layers.

High-resolution transmission electron microscopy (HRTEM) was also used to observe the morphology of the embedded V nanoparticles in the pyrolyzed MIL-47 (V) catalysts. Activated MIL-47 (V) was composed of rectangular particles in the micron size range (Fig. 4a and 4c) [1]. C600, however, showed a morphology that resembled partially destroyed MIL-47 (V) particles (Fig. 4b). Interestingly, instead of generating discernible $V$ nanoparticles, $\mathrm{C} 600$ showed stacks of elongated $V$ features in the HRTEM images (Fig. 4d), where the incorporation of $V$ was confirmed by energy dispersive $X$-ray (EDX) spectroscopy (Fig. S5). Indeed, $\mathrm{C} 600$ contained $\mathrm{VO}_{2}$ crystallites with an average size of $22.7 \mathrm{~nm}$ at the $(-2$ 2 2) facet, as evaluated using the Scherrer equation.

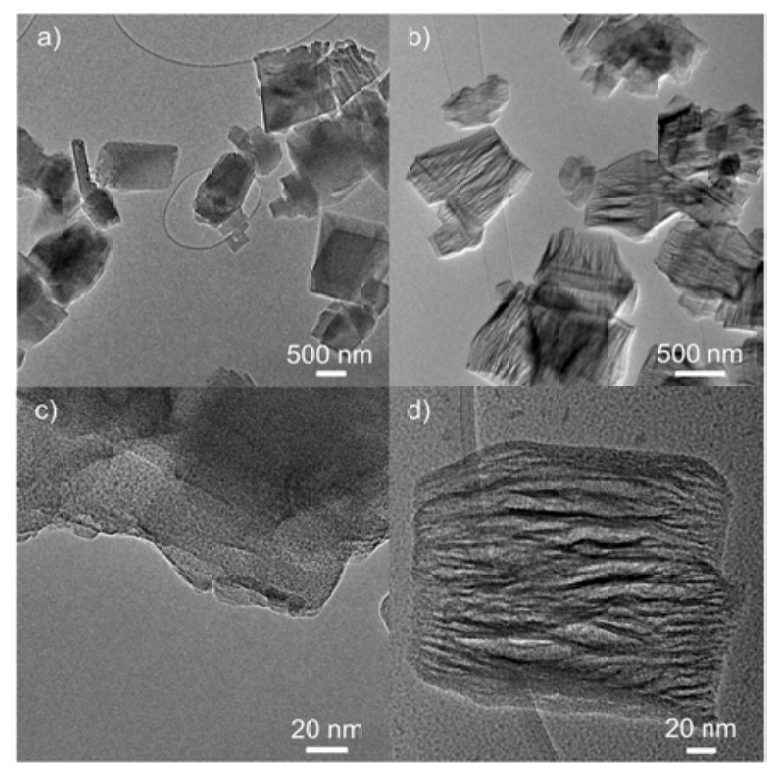

Fig. 4. HRTEM images of MIL-47 (V) ( $a$ and $c$ ) and C600 ( $b$ and $d)$..

In contrast to $\mathrm{C} 600$, HRTEM images of both $\mathrm{C} 1000$ and $\mathrm{C} 1100$ showed that although the original rectangular MIL-47 (V) morphology was maintained, some degradation was observed (Fig. 5a and 5b). This was in line with our previous studies that showed the retention of the macroscopic morphology in 
pyrolyzed MOFs at $1000^{\circ} \mathrm{C}$ or greater $[25,38,39,48]$. In addition, both C1000 and C1100 contained dispersed $V$ nanoparticles (Fig. $5 a$ and $5 b$ ) with average particle sizes of $18.8 \pm 5.9 \mathrm{~nm}$ and $23.1 \pm 6.0 \mathrm{~nm}$ for $\mathrm{C} 1000$ and $\mathrm{C} 1100$, respectively (Fig. 5c-5f). These results were similar to the average sizes of $\mathrm{V}_{8} \mathrm{C}_{7}$ crystallites calculated at the (2 2 2) facet using the Scherrer equation, which yielded values of $14.8 \mathrm{~nm}$ and $16.2 \mathrm{~nm}$ for C1000 and C1100, respectively. Notably, in spite of a far greater amount of $\mathrm{V}$ quantity in C1100 (68.1 wt. \%) compared to V/AC (25.0 wt. \%), the $\mathrm{V}_{8} \mathrm{C}_{7}$ crystallite size at (2 22 ) in C1100 was only $4.5 \mathrm{~nm}$ larger than that in V/AC (11.7 nm). Additionally, V/AC also contained large $V$ oxide crystallites

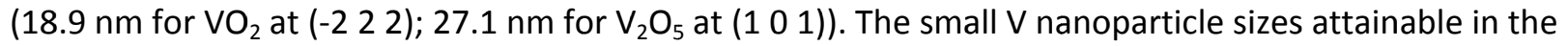
C1100 catalyst again suggested the advantage of the of MOF pyrolysis technique for reducing the aggregation of $\mathrm{V}$ crystallites during catalyst synthesis over the conventional impregnation technique [25, 38].
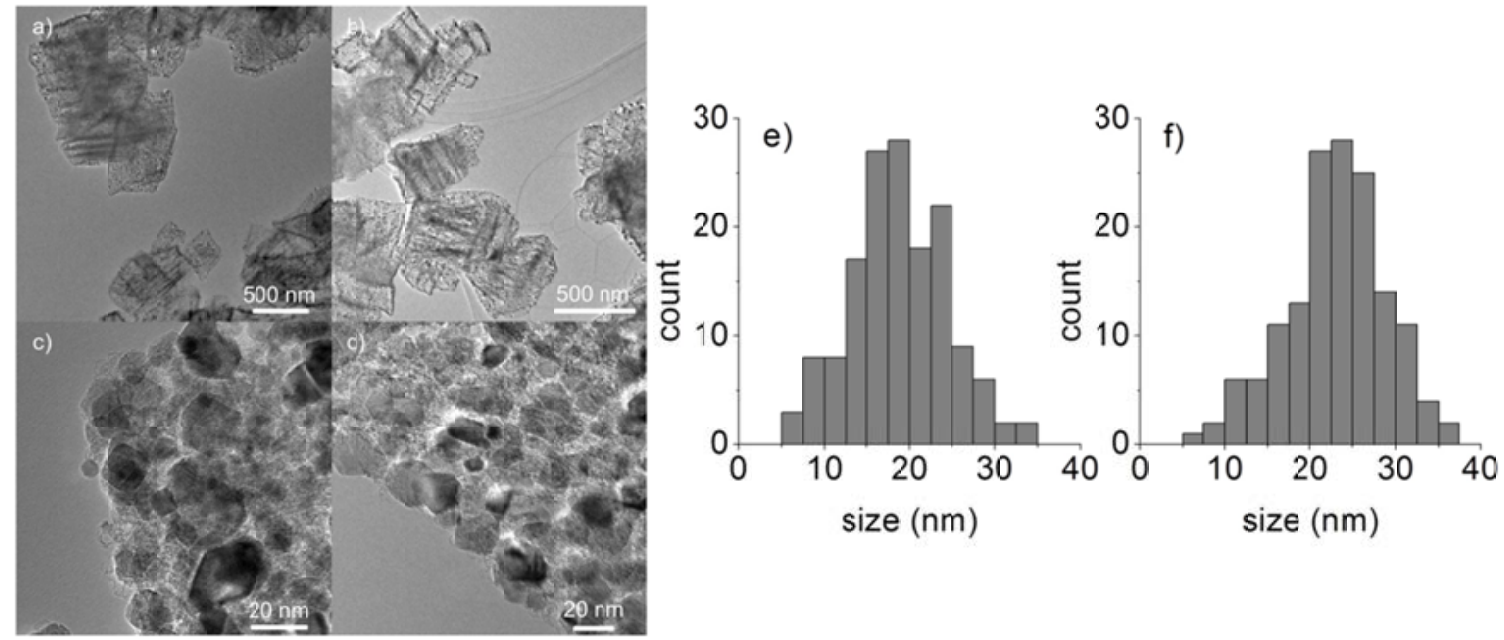

Fig. 5. HRTEM images of C1000 ( $a$ and $c$ ) and C1100 ( $b$ and d). Histograms showed the size distribution of $V$ nanoparticles $(n=150)$ on e) C1000 and f) C1100.

\subsection{Catalytic performance}

The catalytic performance of all resulting catalysts was evaluated in the liquid-phase oxidation of dibenzothiophene (DBT) to form the corresponding sulfoxide and sulfone (Fig. 6a), where tert-butyl 
hydroperoxide (TBHP) was used as an oxidant $[1,38,58]$. The purpose of this study was to determine how the $V$ phase influenced the catalyst activity and stability. Therefore, the C600, C1000, and C1100 materials were selected as catalysts in this study since each catalyst isolated only one bulk phase of $\mathrm{V}$ interested (i.e., $\mathrm{VO}_{2}$ for $\mathrm{C} 600 ; \mathrm{V}_{8} \mathrm{C}_{7}$ for both $\mathrm{V} 1000$ and $\mathrm{V} 1100$ ) and showed similar textural properties $\left(\mathrm{S}_{\text {NLDFT }}\right.$ and $\mathrm{V}_{\mathrm{PORE}}$, etc.). In addition, the catalytic performance of these catalysts was compared to that of V/AC synthesized via impregnation. Catalytic activity of each catalyst was evaluated by determining the initial reaction rate, which was obtained by multiplying the experimentally determined apparent reaction rate constant $\left(k_{a p p}\right)$ with the initial DBT concentration $\left(C_{D B T}, 0\right)$. Apparent reaction rate constants were determined by fitting experimental data to a pseudo- $1^{\text {st }}$-order kinetic model (Fig. S4d and S7) [1, $38,48,58]$. For comparison, the initial reaction rate was normalized with respect to the molar amount of $V$ used in each reaction to provide the value of $-r_{D B T}, 0$. Of note, while a consistent amount of each catalyst was used throughout all recycle runs as described in the experimental section, the amount of $\mathrm{V}$ used in each run was determined via inductively coupled plasma-optical emission spectrometry (ICP-OES) $[1,6]$. ICP-OES was used to quantify the amount of $\mathrm{V}$ present in both the solid (catalyst) and reaction solution post-reaction after separation via filtration (Table S2). The stabilities of the catalysts were also evaluated based on the amount of leached $\mathrm{V}$ species present in the post-reaction solution obtained via ICP-OES analyses (Table 3). 
a)<smiles></smiles>

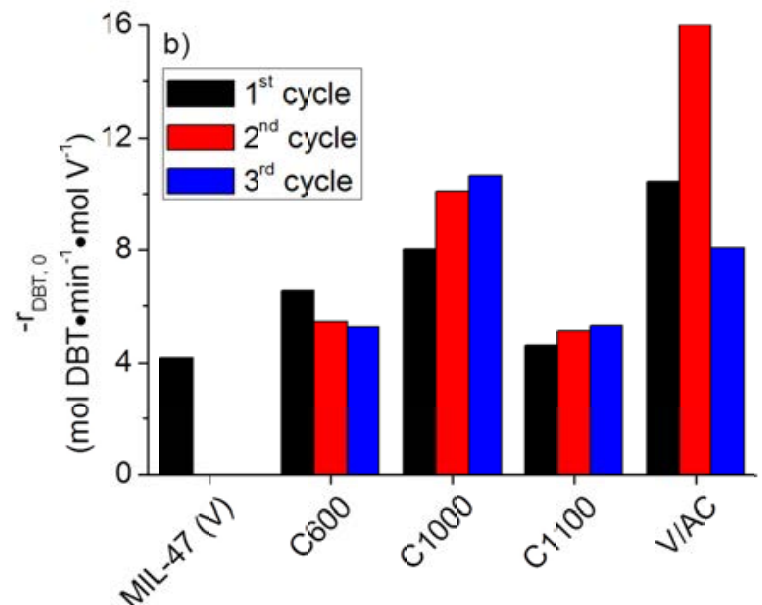

Fig. 6. a) Scheme for the oxidation of dibenzothiophene. b) Initial reaction rates $\left(-r_{D B T}, 0\right)$ for the oxidation of dibenzothiophene with TBHP using the V-based catalysts for multiple consecutive runs at $104( \pm 1){ }^{\circ} \mathrm{C}$.

A blank reaction with no added catalyst showed very little conversion (below $2 \%$ ) and exhibited a low initial reaction rate $\left(\sim 2.3 \times 10^{-5} \mathrm{~mol} \mathrm{DBT} \bullet \mathrm{L}^{-1} \bullet \mathrm{min}^{-1}\right)$ due to the absence of $\mathrm{V}$ active sites to catalyze this reaction (Fig. S6 and S7). The catalysts used in this study, in contrast, showed greater conversions of DBT during the reaction runs (10-60\%) compared to the blank reaction, while showing $100 \%$ selectivities to dibenzothiophene sulfone (Fig. S4 and S6). The activated MIL-47 (V) was active $\left(-r_{\mathrm{DBT}, 0}=4.18 \mathrm{~mol}\right.$ $\mathrm{DBT} \bullet \mathrm{min}^{-1} \bullet \mathrm{mol} \mathrm{V}^{-1}$ ) for this reaction (Fig. 6b); however, we previously reported the destruction of this MOF during the catalytic reaction [1]. Hence, MIL-47 (V) showed severe leaching of V species (43.6 mol. \%) and could not be recovered for subsequent recycle reactions, as shown in Table 3.

Table 3. The amount of $\mathrm{V}$ species leached from the catalysts after each cycle run.

\begin{tabular}{cccc} 
& \multicolumn{3}{c}{ V leaching $^{a, b}(\mathrm{~mol} . \%)$} \\
\cline { 2 - 4 } catalyst & $1^{\text {st }}$ cycle & $2^{\text {nd }}$ cycle $^{\text {rd }}$ cycle \\
\hline MIL-47 (V) & 43.6 & - & - \\
C600 & 24.3 & 13.3 & 9.2 \\
C1000 & 27.8 & 17.6 & 4.8 \\
C1100 & 19.5 & 8.3 & 2.3 \\
V/AC & 60.4 & 51.9 & 54.7 \\
\hline
\end{tabular}


${ }^{a}$ via ICP-OES. ${ }^{b}$ reaction temperature: $104( \pm 1)^{\circ} \mathrm{C}$.

In contrast, pyrolysis of MIL-47 (V) to form carbon catalysts enhanced their chemical resistance to TBHP, as evidenced by the drastic decrease in the amount of $V$ species leached during the $1^{\text {st }}$ cycle (19.524.3 mol. \%) (Table 3). Of additional note, the amount of leached $V$ species of the pyrolyzed catalysts was less than that of the parent MOF, despite the fact that the pyrolyzed catalysts had far higher loadings of $\mathrm{V}$. The increased chemical stability and reduction in leaching of $\mathrm{V}$ of the pyrolyzed catalysts were attributed to the inherent advantages of this synthetic method. During pyrolysis, the $\mathrm{V}$ oxide clusters present in MIL-47 (V) underwent carbothermal reduction, which led to oxidation and elimination of carbon from the MOF structure. This carbon consumption and removal has been postulated to generate concave holes in the carbon support, in which $V$ sites can be firmly anchored [25, $38,53]$. Furthermore, these pyrolyzed catalysts also showed catalytic activities that were similar to or

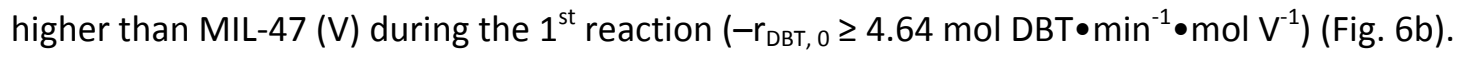

The catalytic activities and stabilities among these catalysts over multiple runs were also compared. Interestingly, C600 showed a continuous decrease in both catalytic activity and leached amount of $\mathrm{V}$ species during each of the subsequent recycle runs (Table 3 and Fig. 6b). This indicated each reaction cycle was likely controlled by the leached V oxide species (Fig. S8). These active V oxide species were likely $\mathrm{VO}_{2}\left(\mathrm{~V}^{4+}\right)$ and $\mathrm{V}_{2} \mathrm{O}_{5}\left(\mathrm{~V}^{5+}\right)$ based on numerous studies found in the literature, which demonstrated that these leached $V$ oxide species can catalyze various liquid-phase oxidation reactions $[1,5,6,11]$. Leached $\mathrm{V}_{2} \mathrm{O}_{3}\left(\mathrm{~V}^{3+}\right)$ species (as observed in the XP spectrum of $\mathrm{C} 600$ prior to the $1^{\text {st }}$ run), in contrast, were unlikely to enhance its catalytic activity based on previous studies that suggested $\mathrm{V}^{3+}$ is much less active for oxidation reactions compared to $\mathrm{V}^{4+}$ and $\mathrm{V}^{5+}$ species [21,63-65]. It should be noted, however, based on various reports $[21,63-65]$, it has been hypothesized that leached $V^{3+}$ species could be oxidized 
to generate active $\mathrm{V}$ oxide species (i.e., $\mathrm{V}^{4+}$ or $\mathrm{V}^{5+}$ ) in the presence of TBHP and subsequently catalyze the reaction as activated, unsupported catalytic sites (Fig. S8). In our study, we speculated that, although the supported $\mathrm{V}$ oxide species (i.e., $\mathrm{V}^{4+}$ and $\mathrm{V}^{5+}$ ) could still catalyze this reaction, the decrease in the activity of $\mathrm{C} 600$ during each recycle run was due mainly to the loss of active $\mathrm{V}$ oxide species during vacuum filtration post reaction. This was further validated by a hot filtration study, which is discussed later.

The C1000 material exhibited a higher activity $\left(-r_{\mathrm{DBT}, 0}=8.01 \mathrm{~mol} \mathrm{DBT} \cdot \mathrm{min}^{-1} \bullet \mathrm{mol}^{-1}\right)$ than $\mathrm{C} 600\left(-\mathrm{r}_{\mathrm{DBT}, 0}\right.$ $\left.=6.55 \mathrm{~mol} \mathrm{DBT} \bullet \mathrm{min}^{-1} \bullet \mathrm{mol} \mathrm{V}^{-1}\right)$ and $\mathrm{C} 1100\left(-\mathrm{r}_{\mathrm{DBT}, 0}=4.64 \mathrm{~mol} \mathrm{DBT} \bullet \mathrm{min}^{-1} \bullet \mathrm{mol} \mathrm{V}^{-1}\right)$ during the $1^{\text {st }}$ run. This was unanticipated because the $\mathrm{C} 1000$ contained a relatively larger size of $\mathrm{V}$ nanoparticles compared to the $\mathrm{C} 600$. In addition, the $\mathrm{C} 1000$ showed the largest amount of leached $\mathrm{V}$ species (27.8 mol. \%). In contrast, in spite of showing a continuous decrease in the leached amount of V species, C1000 exhibited an increase in the catalytic activity after each subsequent recycle experiment (i.e. $2^{\text {nd }}$ and $3^{\text {rd }}$ reactions) (Table 3 and Fig. 6b). This indicated that the leached (unsupported) $V$ species (i.e., $V$ carbide $\left(\mathrm{V}^{\delta+}\right)$ and $\mathrm{V}^{3+}$ detected in its XP spectrum prior to the $1^{\text {st }}$ run) were not the primary source of activity, in spite of their potential oxidation by TBHP to generate active $\mathrm{V}$ oxide species (Fig. S9b). This result, rather, suggested the supported $\mathrm{V}$ species were activated by TBHP oxidation via either $\mathrm{V}^{\delta+} \rightarrow \mathrm{V}^{4+} / \mathrm{V}^{5+}$ or $\mathrm{V}^{3+} \rightarrow$ $\mathrm{V}^{4+} / \mathrm{V}^{5+}$ and played a role as a primary source of activity in C1000 (Fig. S9a). Moreover, it is likely that the $\mathrm{V}^{\delta+}$ phase can reduce the leaching of active $\mathrm{V}$ species during the reaction due to enhanced chemical stability $[25-30,66,67]$ and/or enhanced embedment on the carbon surface facilitated via carbothermal $V$ reduction $[25,46,53]$, compared to analogous oxide species. This can be evidenced by the $3^{\text {rd }}$ recycle run of $\mathrm{C} 1000$, which showed the highest catalytic activity $\left(-\mathrm{r}_{\mathrm{DBT}, 0}=10.7 \mathrm{~mol} \mathrm{DBT} \bullet \mathrm{min}^{-1} \bullet \mathrm{mol} \mathrm{V}^{-1}\right)$ while leaching the least amount of $\mathrm{V}$ species $(4.8 \mathrm{~mol} . \%)$ among the reaction runs. The increase in the activities during the multiple recycles could be due to the oxidation of both $\mathrm{V}^{\delta+}$ and $\mathrm{V}^{3+}$ species by TBHP 
to generate active $\mathrm{V}$ oxide species supported on the carbon (Fig. S9a). During each reaction, the amount of these active, supported species present on the surface can increase compared to the catalysts used at the previous run due to additional exposure to TBHP.

C1100, however, leached the least amount of $V$ species at each reaction cycle (2.3-19.5 mol. \%) compared to both $\mathrm{C} 600$ and $\mathrm{C} 1000$ (4.8-27.8 mol. \%), while exhibiting increasingly higher catalytic

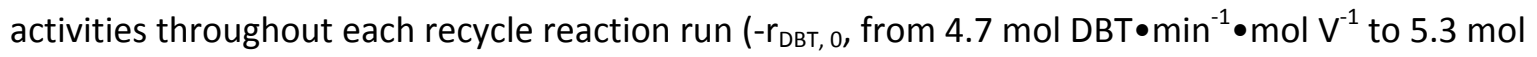
$\left.\mathrm{DBT} \bullet \mathrm{min}^{-1} \bullet \mathrm{mol} \mathrm{V}^{-1}\right)$. These increases in activities were expected given the catalytic results of C1000 and our hypothesis that supported $\mathrm{V}$ species could be oxidized to generate active $\mathrm{V}$ oxide species supported on carbon during the reaction, the amount of which could be continually increased throughout the recycle runs. The formation of the $\mathrm{V}$ oxide species after the reaction was evidenced by the XP spectrum of $\mathrm{C} 1100$ after the $1^{\text {st }}$ run, which showed the presence of $\mathrm{V}$ oxide species (Fig. S10) that were not detectable on the catalyst prior to the reaction. The lowest amount of leaching of $V$ species was also anticipated because the $\mathrm{C} 1100$ solely contained $\mathrm{V}$ carbide $\left(\mathrm{V}^{\delta+}\right)$ species prior to the reaction according to XP spectrum (Table 2 and Fig. 3), and therefore may leach a lower amount of $\mathrm{V}$ oxide species during the reaction than $\mathrm{C} 1000$ due in potential to the enhanced stability of $\mathrm{V}^{\delta+}$ over $\mathrm{V}$ oxides, as discussed previously. Several important conclusions can be suggested from these catalysis results: 1) the catalysts incorporating V carbide (C1000 and C1100) were more chemically stable and could be more effectively recycled than the catalyst incorporating $\mathrm{V}$ oxide $(\mathrm{C600})$ and 2 ) the $\mathrm{V}$ carbide catalysts could perform the reaction through supported $\mathrm{V}$ species, whereas the $\mathrm{V}$ oxide catalyst may have had a significant contribution to activity from unsupported $\mathrm{V}$ oxide species.

In contrast to $\mathrm{C} 1100$, which showed a slight increase in activities over recycle runs, V/AC catalysts showed an increase in activity at the $2^{\text {nd }}$ cycle and a decrease in activity at the $3^{\text {rd }}$ cycle (Fig. 6b). This was likely attributed to the co-presence of $\mathrm{V}$ oxide and $\mathrm{V}$ carbide species in the V/AC prior to the $1^{\text {st }}$ reaction 
run, as evidenced by its XRD pattern (Fig. 2), which led to multiple different contributions from both supported and unsupported $\mathrm{V}$ species active for this reaction. This suggests that at least one type of active sites for catalyzing this reaction was a supported V species on AC. However, V/AC showed substantial V leaching (51.9-60.4 mol. \%) throughout each sequential recycle run, which ultimately led to a significant reduction in activity by the $3^{\text {rd }}$ reaction cycle. Furthermore, throughout the three consecutive reactions, V/AC lost a total $\sim 80 \mathrm{~mol}$. \% of its initial V loading. Therefore, it is expected that the activities of V/AC will quickly be reduced to zero within a short number of recycle runs. In contrast, C1000 showed a consistent increase in activity and C1100 maintained a consistent activity throughout five consecutive runs (Fig. S11). Additionally, C1000 and C1100 only leached a total of 35 and 18 mol. \% of initial V loadings throughout five reaction cycles, respectively. These results demonstrated their enhanced stabilities and recyclabilities compared to V/AC, as well as the value of MOF pyrolysis as a viable synthetic technique for producing carbon-supported catalysts with enhanced stability. These results once again demonstrated the value of MOF pyrolysis as a viable synthetic technique for producing carbon-supported catalysts with enhanced stability.

In order to further investigate the catalytic activity contributed by supported and unsupported $\mathrm{V}$ species on the pyrolyzed MIL-47 (V) catalysts, hot filtration experiments were also performed. As shown in Table 3, all catalysts suffered from $V$ leaching during this reaction. Therefore, there is a possibility that the active sites of these catalysts may be leached, unsupported $V$ species which were weakly bound to the catalysts prior to the reaction $[6,7,11,15]$. As evidenced by HRTEM images, these pyrolyzed catalysts contained $V$ nanoparticles with sizes of $\sim 23 \mathrm{~nm}$ or below. Some of these small nanoparticles can leach from the carbon surface and are small enough to pass through the filter paper during a hot filtration experiment. These leached nanoparticles could then continuously turnover DBT. The hot filtration study of $\mathrm{C} 600$ containing a bulk $\mathrm{V}$ oxide phase showed a steady increase in turnover number (TON, moles of DBT converted per moles of $\mathrm{V}$ ) with time even after the solid catalyst was removed from the reaction mixture (Fig. 7). Indeed, this experiment provided evidence that the unsupported $V$ species 
leached from C600 could primarily catalyze the reaction. This was in contrast to reactions employing both $\mathrm{C} 1000$ and $\mathrm{C} 1100$ containing bulk V carbide phases as catalysts, which showed little or no increase in the TON with time after their separation from the reaction mixture. This slight increase could be due in part to the leached $\mathrm{V}^{\delta+}$ or $\mathrm{V}^{3+}$ species activated via oxidation in the presence of TBHP during the reaction, as stated previously (Fig. S9b). These results provided further supporting evidence of our hypotheses about 1 ) the contribution of supported V species innate to $\mathrm{C} 1000$ and $\mathrm{C} 1100$ for catalyzing the reaction and 2) the enhanced stability of $V$ carbide catalysts compared to the $V$ oxide catalysts synthesized from pyrolysis of MIL-47 (V).

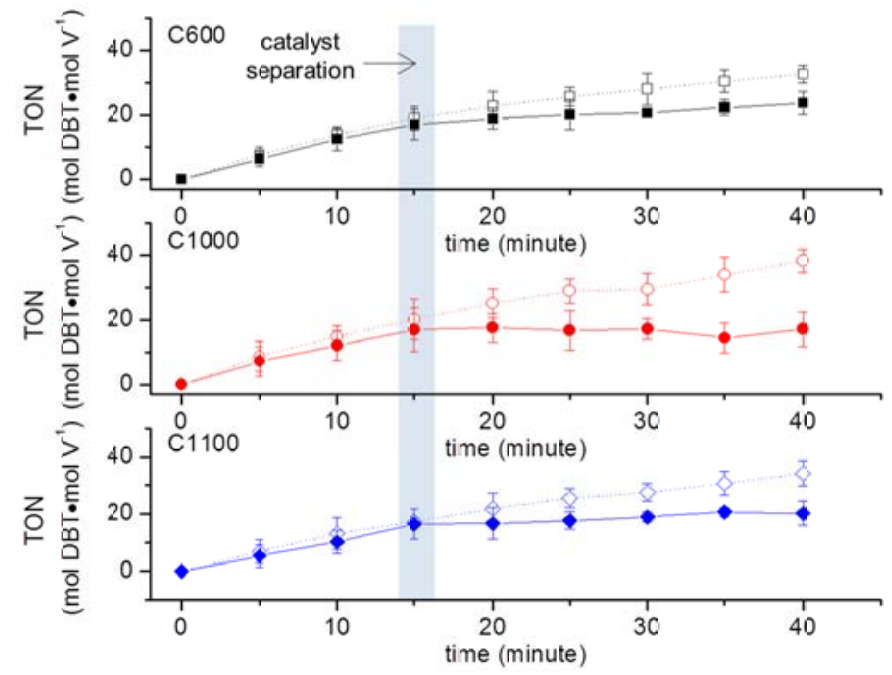

Fig. 7. Hot filtration study (turnover number (TON) versus time) of the catalysts at $75( \pm 1)^{\circ} \mathrm{C}$. Empty and filled symbols indicate normal and hot filtration runs, respectively..

\section{Conclusions}

This study has demonstrated several advantages in the use of MIL-47 (V) as the template, C source, and $\mathrm{V}$ precursor to form a new series of $\mathrm{V}$-based carbon catalysts through pyrolysis. The large amount of V species incorporated into this MOF provided a large amount of active $V$ sites (36-68 wt. \%) in the resulting catalysts after pyrolysis. The porous nature of this MOF also provided final catalysts with moderate surface areas $\left(300-400 \mathrm{~m}^{2} \mathrm{~g}^{-1}\right)$ and high mesoporosities ( $\mathrm{V}_{\mathrm{MESO}} / \mathrm{V}_{\text {PORE }}$ of $\left.0.84-0.91\right)$, which can 
enhance the accessibility of larger subtrates to $V$ sites during catalytic reactions. In addition, in spite of high loadings of $V$ in the final catalysts, the size of $V$ crystallites was small (below $16 \mathrm{~nm}$ ) with a high dispersion. Most importantly, the active $\mathrm{V}$ phases in the catalysts were altered through the change in the pyrolysis temperatures from 600 to $1100{ }^{\circ} \mathrm{C}$, as evidenced by their XRD patterns and the XP spectra. Both bulk phases (via XRD) and surface phases (via XPS) of $\mathrm{V}$ species can be varied from $\mathrm{V}$ oxide to $\mathrm{V}$ carbide by increasing the pyrolysis temperature. The control material, $\mathrm{V}$ on activated carbon, synthesized via a conventional impregnation technique could further validate the benefits associated with the MIL-47 (V) pyrolysis. This control material showed lower mesoporosity ( $\mathrm{V}_{\mathrm{MESO}} / \mathrm{V}_{\text {PORE }}$ of 0.63$)$, lower V quantity (25 wt. \%), and larger V crystallites (below $27 \mathrm{~nm}$ ) compared to MIL-47 (V) pyrolyzed under the identical condition (i.e., $1100^{\circ} \mathrm{C}$ ). Notably, in contrast to pyrolyzed MIL-47 (V) catalysts, the isolation of a bulk V carbide phase in the V/AC could not be accomplished even after pyrolysis at $1100{ }^{\circ} \mathrm{C}$. The catalytic performance of all resulting catalysts was also evaluated and compared in the oxidation of dibenzothiophene. The $\mathrm{V}$ oxide catalyst $(\mathrm{C} 600)$ showed significant leaching of highly active $\mathrm{V}$ species $\left(\mathrm{V}^{4+}\right.$ and $\mathrm{V}^{5+}$ ) during each reaction run. Furthermore, hot filtration studies provided evidence that these unsupported $\mathrm{V}$ species predominantly performed the reaction. In contrast, aside from showing good activities in this reaction, the $\mathrm{V}$ carbide catalysts ( $\mathrm{C} 1000$ and $\mathrm{C} 1100)$ showed less leaching of $\mathrm{V}$ species. Furthermore, hot filtration study suggested that the activities of these unsupported $\mathrm{V}$ species were likely insignificant compared to the supported V species in both C1000 and C1100 for this reaction. This may likely be attributed to the advantages of the $V$ carbide over the oxide counterparts, which can provide enhanced chemical stability and enhanced anchoring on the carbon support during this reaction. In particular, the amount of $\mathrm{V}$ leaching in these catalysts was far smaller compared to V/AC, thus providing another reason to synthesized catalysts by pyrolyzing MOFs.

\section{Acknowledgements}


Acknowledgement is made to the Donors of the American Chemical Society Petroleum Research Fund for support of this research (PRF\# 53874-DNI10). The authors thank the University of Notre Dame for startup funds. We thank the Center for Sustainable Energy at Notre Dame (CSEND) Materials characterization facilities for the use of PHI VersaProbe II X-Ray Photoelectron Spectrometer and Bruker D8 Advance Davinci Powder X-Ray Diffractometer. We acknowledge support of the National Science Foundation through MRI award 1126374 for the XPS data in this paper. We thank the Center for Environmental Science and Technology at Notre Dame and the Notre Dame Integrated Imaging Facilities for partial support through access to their facilities and instrumentation.

\section{References}

[1] N.D. McNamara, G.T. Neumann, E.T. Masko, J.A. Urban, J.C. Hicks, J. Catal. 305 (2013) 217-226.

[2] M.A. Ramos-Luna, L. Cedeño-Caero, Ind. Eng. Chem. Res. 50 (2011) 2641-2649.

[3] L. Cedeño-Caero, H. Gomez-Bernal, A. Fraustro-Cuevas, H.D. Guerra-Gomez, R. Cuevas-Garcia, Catal. Today 133-135 (2008) 244-254.

[4] O. González-García, L. Cedeño-Caero, Catal. Today 150 (2010) 237-243.

[5] Y. Deng, C. Lettmann, W.F. Maier, Appl. Catal., A 214 (2001) 31-46.

[6] K. Leus, M. Vandichel, Y.-Y. Liu, I. Muylaert, J. Musschoot, S. Pyl, H. Vrielinck, F. Callens, G.B. Marin, C. Detavernier, P.V. Wiper, Y.Z. Khimyak, M. Waroquier, V. Van Speybroeck, P. Van Der Voort, J. Catal. 285 (2012) 196-207.

[7] Y.-Y. Liu, K. Leus, M. Grzywa, D. Weinberger, K. Strubbe, H. Vrielinck, R. Van Deun, D. Volkmer, V. Van Speybroeck, P. Van Der Voort, Eur. J. Inorg. Chem. 2012 (2012) 2819-2827.

[8] A.V. Ramaswamy, S. Sivasanker, Catal Lett 22 (1993) 239-249.

[9] G.C. Behera, K.M. Parida, Applied Catalysis A: General 413-414 (2012) 245-253.

[10] L. Rout, P. Nath, T. Punniyamurthy, Adv. Synth. Catal. 349 (2007) 846-848.

[11] S. Shylesh, A.P. Singh, J. Catal. 228 (2004) 333-346.

[12] K. Leus, G. Vanhaelewyn, T. Bogaerts, Y.-Y. Liu, D. Esquivel, F. Callens, G.B. Marin, V. Van Speybroeck, H. Vrielinck, P. Van Der Voort, Catal. Today 208 (2013) 97-105.

[13] P. Van Der Voort, M. Baltes, E.F. Vansant, J. Phys. Chem. B 103 (1999) 10102-10108.

[14] K. Leus, S. Couck, M. Vandichel, G. Vanhaelewyn, Y.Y. Liu, G.B. Marin, I. Van Driessche, D. Depla, M. Waroquier, V. Van Speybroeck, J.F. Denayer, P. Van der Voort, PCCP 14 (2012) 15562-15570.

[15] K. Leus, I. Muylaert, M. Vandichel, G.B. Marin, M. Waroquier, V. Van Speybroeck, P. Van der Voort, Chem. Commun. 46 (2010) 5085-5087.

[16] N.N. Trukhan, V.N. Romannikov, E.A. Paukshtis, A.N. Shmakov, O.A. Kholdeeva, J. Catal. 202 (2001) 110-117.

[17] P. Villabrille, G. Romanelli, P. Vázquez, C. Cáceres, Appl. Catal. A 334 (2008) 374-380.

[18] P. Wessig, Gerngro, S. Pape, P. Bruhns, J. Weber, RSC Adv. 4 (2014) 31123-31129.

[19] J. Jeromenok, J. Weber, Langmuir 29 (2013) 12982-12989. 
[20] O.A. Kholdeeva, O.V. Zalomaeva, Coord. Chem. Rev. 306, Part 1 (2016) 302-330.

[21] M. Hävecker, N. Pinna, K. Weiß, H. Sack-Kongehl, R.E. Jentoft, D. Wang, M. Swoboda, U. Wild, M. Niederberger, J. Urban, D.S. Su, R. Schlögl, J. Catal. 236 (2005) 221-232.

[22] B.M. Weckhuysen, D.E. Keller, Catal. Today 78 (2003) 25-46.

[23] I.E. Wachs, B.M. Weckhuysen, Appl. Catal. A 157 (1997) 67-90.

[24] E.V. Kondratenko, O. Ovsitser, J. Radnik, M. Schneider, R. Kraehnert, U. Dingerdissen, Appl. Catal. A 319 (2007) 98-110.

[25] J. Kim, G.T. Neumann, N.D. McNamara, J. Hicks, J. Mater. Chem. A 2 (2014) 14014-14027.

[26] Z. Jiang, W.E. Rhine, Chem. Mater. 3 (1991) 1132-1137.

[27] K.K. Lai, H.H. Lamb, Chem. Mater. 7 (1995) 2284-2292.

[28] Y. Shin, X.S. Li, C. Wang, J.R. Coleman, G.J. Exarhos, Adv. Mater. 16 (2004) 1212-1215.

[29] C.-H. Huang, D. Gu, D. Zhao, R.-A. Doong, Chem. Mater. 22 (2010) 1760-1767.

[30] Q. Yan, C. Wan, J. Liu, J. Gao, F. Yu, J. Zhang, Z. Cai, Green Chem. 15 (2013) 1631-1640.

[31] R.B. Levy, M. Boudart, Science 181 (1973) 547-549.

[32] S.T. Oyama, Catal. Today 15 (1992) 179-200.

[33] J.B. Joo, J.S. Kim, P. Kim, J. Yi, Mater. Lett. 62 (2008) 3497-3499.

[34] J.B. Joo, J. Kim, P. Kim, J. Yi, J. Nanosci. Nanotechnol. 10 (2010) 3397-3401.

[35] J. Mrowiec-Białoń, A.B. Jarzębski, O.A. Kholdeeva, N.N. Trukhan, V.I. Zaikovski, V.V. Kriventsov, Z. Olejniczak, Appl. Catal. A 273 (2004) 47-53.

[36] I.D. Ivanchikova, M.K. Kovalev, M.S. Mel'gunov, A.N. Shmakov, O.A. Kholdeeva, Catal. Sci. Technol. 4 (2014) 200-207.

[37] O.A. Kholdeeva, M.S. Mel'gunov, A.N. Shmakov, N.N. Trukhan, V.V. Kriventsov, V.I. Zaikovskii, M.E. Malyshev, V.N. Romannikov, Catal. Today 91-92 (2004) 205-209.

[38] J. Kim, N.D. McNamara, T.H. Her, J.C. Hicks, ACS Appl. Mater. Interfaces 5 (2013) 11479-11487.

[39] J. Kim, A.G. Oliver, J.C. Hicks, CrystEngComm (2015).

[40] B. Liu, H. Shioyama, H. Jiang, X. Zhang, Q. Xu, Carbon 48 (2010) 456-463.

[41] Z. Hu, C. Chen, H. Meng, R. Wang, P.K. Shen, H. Fu, Electrochem. Commun. 13 (2011) 763-765.

[42] S. Han, Y. Yun, K.W. Park, Y.E. Sung, T. Hyeon, Adv. Mater. 15 (2003) 1922-1925.

[43] G. Srinivas, V. Krungleviciute, Z.-X. Guo, T. Yildirim, Energy Environ. Sci. 7 (2014) 335-342.

[44] B. Liu, H. Shioyama, T. Akita, Q. Xu, J. Am. Chem. Soc. 130 (2008) 5390-5391.

[45] M.O. Guerrero-Pérez, J.M. Rosas, R. López-Medina, M.A. Bañares, J. Rodríguez-Mirasol, T. Cordero, J. Phys. Chem. C 116 (2012) 20396-20403.

[46] Y. Shen, J. Mater. Chem. A 3 (2015) 13114-13188.

[47] H.L. Jiang, B. Liu, Y.Q. Lan, K. Kuratani, T. Akita, H. Shioyama, F. Zong, Q. Xu, J. Am. Chem. Soc. 133 (2011) 11854-11857.

[48] N.D. McNamara, J. Kim, J.C. Hicks, Energy Fuels 30 (2016) 594-602.

[49] S.J. Yang, S. Nam, T. Kim, J.H. Im, H. Jung, J.H. Kang, S. Wi, B. Park, C.R. Park, J. Am. Chem. Soc. 135 (2013) 7394-7397.

[50] V.P. Santos, T.A. Wezendonk, J.J.D. Jaén, A.I. Dugulan, M.A. Nasalevich, H.-U. Islam, A. Chojecki, S. Sartipi, X. Sun, A.A. Hakeem, A.C.J. Koeken, M. Ruitenbeek, T. Davidian, G.R. Meima, G. Sankar, F. Kapteijn, M. Makkee, J. Gascon, Nat. Commun. 6 (2015).

[51] L. Wang, Y. Zhang, X. Li, Y. Xie, J. He, J. Yu, Y. Song, Sci. Rep. 5 (2015) 14341.

[52] K. Barthelet, J. Marrot, D. Riou, G. Férey, Angew. Chem. Int. Ed. 41 (2002) 281-284.

[53] Q. Song, J. Cai, J. Zhang, W. Yu, F. Wang, J. Xu, Chin. J. Catal. 34 (2013) 651-658.

[54] A.V. Neimark, Y. Lin, P.I. Ravikovitch, M. Thommes, Carbon 47 (2009) 1617-1628.

[55] Y. Xu, Q. Liu, Y. Zhu, Y. Liu, A. Langrock, M.R. Zachariah, C. Wang, Nano Lett. 13 (2013) 470-474.

[56] J. Kim, A.G. Oliver, J.C. Hicks, CrystEngComm 17 (2015) 8015-8020. 
[57] N. Ji, T. Zhang, M. Zheng, A. Wang, H. Wang, X. Wang, Y. Shu, A.L. Stottlemyer, J.G. Chen, Catal. Today 147 (2009) 77-85.

[58] N.D. McNamara, J.C. Hicks, ACS Appl. Mater. Interfaces 7 (2015) 5338-5346.

[59] D.A. Bulushev, L. Kiwi-Minsker, A. Renken, Catal. Today 57 (2000) 231-239.

[60] J.M. López Nieto, Top Catal 15 (2001) 189-194.

[61] Z. Zhao, Y. Liu, H. Cao, S. Gao, M. Tu, Powder Technol. 181 (2008) 31-35.

[62] A. Centrone, T. Harada, S. Speakman, T.A. Hatton, Small 6 (2010) 1598-1602.

[63] I.E. Wachs, J.-M. Jehng, W. Ueda, J. Phys. Chem. B 109 (2005) 2275-2284.

[64] T. Feng, J.M. Vohs, J. Catal. 208 (2002) 301-309.

[65] G.S. Wong, M.R. Concepcion, J.M. Vohs, Surf. Sci. 526 (2003) 211-218.

[66] V.V. Rudneva, G.V. Galevskii, Russ. J. Non-Ferrous Met. 48 (2007) 143-147.

[67] C. Aguzzoli, C.A. Figueroa, F.S. de Souza, A. Spinelli, I.J.R. Baumvol, Surf. Coat. Technol. 206 (2012) 2725-2731. 